\title{
МОДЕЛИРОВАНИЕ СЕЙСМИЧЕСКИХ ВОЛНОВЫХ ПОЛЕЙ ПРИ РЕЩЕНИИ ПРИКЛАДНЫХ ЗАДАЧ СЕЙСМОРАЗВЕДКИ
}

Гонтаренко И.А., Гуленко В.И.

(Кубанский Государственный Университет)

Пакет программ «ВОЛНА-М» разработан на кафедре геофизики геологического факультета КубГУ и предназначен для моделирования сейсмических волновых полей применительно к задачам МОВ или ВСП. В основе программ моделирования лежит набор процедур, реализующих численное решение системы уравнений Кнотта-Цёппритца в комплексной области и обеспечивающих корректный расчет коэффициентов отражения и прохождения, в том числе, и для закритических углов дадения.

Используемый лучевой подход позволяет учитывать образование обменных волн, изменение отражающих свойств границ при наклонном падении волн на них, влияние кривизны границ и волновых фронтов, линейно-зависимое от частоты поглощение волн в среде. Расчет волн в программах моделирования осуществляется в частотной области в соответствии с известными положениями теории распространения упругих волн в многослойной среде с криволинейньми границами с учетом поглошения и с учетом изменения формы импульсов при полном внутреннем отражении, при этом построение сейсмических трасс во временной области осуществляется обратным преобразованием Фурье.

Рассмотрим основные области применения пакета программ «ВОЛНА-М».

1. На этапе проектирования полевьх работ до выполнения полевых наблюдений моделирование волновых полей может успешно применяться для выбора параметров расстановки и системы набтюдений, что позволяет обеспечить наилучшее прослеживание целевых волн на основе теоретических оценок их динамических и кинематических характеристик, особенно в условиях сложного геологического строения исследуемой толщи.

Применение программы из пакета «ВОЛНАМ» для моделирования волнового поля на вертикальном профиле позволяет более обоснованно выбрать как удаления пунктов возбуждения, так и интервалы пунктов наблюдения в скважине, а также проанализировать сравнительную интенсивность разных составляющих при трехкомпонентном приеме упругих колебаний. В качестве примера в работе приведены результаты моделирования волнового поля (годографы прямой и отраженных монотипных и обменных волн, амплитудные графики и сейсмограммы ВСП) на вертикальном профиле скв. Азовская 114 Краснодарского края и сопоставление их с реальными экспериментальными данными.

2. Особенно эффективно применение моделирования в случае сложного строения изучаемой толщи, так как позволяет детально проанализировать структуру волнового поля и влияние на нее геометрических и упругих параметров разреза. Примером таких объектов могут быть структуры со сложной геометрией отражающих поверхностей, приводяших к образованию волн с каустиками и

появлению петель на годографах, слои с инверсией скорости сейсмических волн, слои с высоким поглощением упругих волн и т.п.

3. На этапе обработки данньх нередко возникает задача оценка корректности выбранного графа и эффективности применяемых процедур применительно к некоторому конкретному изучаемому объекту. Наиболее просто эта задача может быть решена применением этого же графа к совокупности модельных сейсмограмм, полученных для модели среды, соответствующей параметрам изучаемого объекта. Использование наборов модельных сейсмограмм, имитирующих профильные наблюдения на известньх геологических моделях, с последующей обработкой этих сейсмограмм по экспериментальному графу позволяет осуществлять отладку ил тестирование новых алгоритмов и программ, расширяющих возможности стандартных пакетов обработки сейсмических данных. В качестве примера в работе рассмотрено опробование на такой модели новой программы миграции в т-р области в сравнении со стандартной программой конечно-разностной миграции.

\section{ЛИТЕРАТУРА}

1. Шерифф Р., Гелдарт Л, Сейсморазведка: в 2-х томах. Пер. с англ. - М.: Мир, 1987

2. О.К. Кондратьев. Сейсмические волны в поглощающих средах. - М.: Недра, 1986, - 176 c. 